\title{
Problems and Issues of Environmental Liability Insurance*
}

\author{
by Howard Kunreuther**
}

\section{Introduction}

The market for environmental impairment liability (EIL) insurance coverage in the United States has dried up. Most insurers are not offering coverage; reinsurers have withdrawn from the market. Hence manufacturers who must process or dispose of toxic substances have difficulty protecting themselves against liability suits for pollution damages. The problem is compounded because federal and state environmental regulations require treatment, storage and disposal facilities for hazardous waste to meet financial responsibility requirements. In addition, to operate, all hazardous waste facilities are required to have third party bodily injury and property damage coverage, either through private insurance, self-insurance or some combination of such coverages. With EIL coverage unavailable, facilities are in danger of being closed because they cannot meet these financial responsibility requirements. ${ }^{1}$

Similarly, the absence of insurance has significantly slowed the cleanup of existing dangerous sites in the United States. Proper risk assessment and risk management of cleanup operations, with insurance industry participation, will remain a critical issue in assuring that urgently needed cleanup work is accomplished with due speed.

While there are many explanations for the present insurance crisis, scholars and industry experts agree that a fundamental problem is the insurability of environmental liabilities

* This research is supported by the Wharton Center for Risk and Insurance. Special thanks to Leslie Cheek, Dennis Connolly, Patricia Danzon, Neil Doherty, Rajeev Gowda, Paul Kleindorfer, Jack Morrison, Mark Pauly and Michael Willingham for helpful discussions. The paper was stimulated by the Wharton School Conference on "The Role of Insurance and Compensation in Environmental Pollution Problems" in May 1986. An earlier version was presented at a Department of Public Policy and Management seminar where I received useful comments and suggestions.

** Professor, Director of the Center for Risk and Decision Processes. The Wharton School, University of Pennsylvania.

1 This description of problems arising from the U.S. insurance crisis draws on remarks of Lee Thomas, Administrator of the U.S. Environmental Protection Agency, as presented at the Wharton School Workshop on the role of Insurance and Compensation in Environmental Pollution Problems, May 15, 1986. An Executive Summary of the Workshop is available from the Wharton Risk and Decision Processes Center. 
per se. In this regard, familiar remedies including better risk identification, risk assessment and risk management, self-insurance, industry pooling and government-industry joint insurance programs may all have important roles to play, but they also have well-known limitations. Hence an analysis of the appropriate role for insurance and the insurance industry in managing such risks is a central issue for understanding effective environmental risk management.

This paper develops a conceptual framework for analysing the environmental pollution problem by drawing on the work of Baruch Berliner (1982) and others who have recently been concerned with the limits of insurability of risks. ${ }^{2}$ Although the paper will focus primarily on the problems facing the United States, recent commentaries on the international situation have noted similar difficulties in Europe. (Kleindorfer and Kunreuther 1987).

\section{Nature of the Problem ${ }^{3}$}

History of Pollution Insurance. Until recently the insurance industry has always provided some type of pollution coverage. Prior to 1966 coverage was offered as part of a Comprehensive General Liability (CGL) policy and usually covered pollution arising from sudden and accidental incidents. Larger firms, however, were able to purchase "occurrence coverage" which insured against exposure to pollution, such as groundwater leakage from a toxic landfill, that might result in disease in the future.

After the freighter Torrey Canyon went aground off the coast of England in 1967, causing environmental damage through the release of a substantial amount of its cargo of oil, and an oil platform blew out off Santa Barbara in 1969, the insurance industry excluded any pollution coverage that was not sudden and accidental.

In the early 1970 s the industry developed a new policy form to cover gradual pollution incidents (e.g. damages or personal injuries from air pollution emissions, water pollution or solid waste disposal). These forms, introduced initially through the London market, provided coverage on a claims made basis. Under a claims made policy, the insurer provides coverage if the claim for damages because of bodily injury or property damage is first made during the policy period. This type of insurance protection differs from an occurrence poli$c y$, which provides coverage for bodily injury and property damage that occurs during the policy period even if a claim is filed 10 or 20 years later.

In response to Congressional legislation imposing financial responsibility requirements on those who operate hazardous waste facilities or are cleaning up the waste, the Insurance Sevices Office (ISO), the industry's largest insurance rating organization, developed a pollution liability insurance policy in the fall of 1981 . This policy, written on a claims made basis, covered the same type of incidents as an EIL policy but was broader in that it provided protection against both sudden and gradual pollution.

\footnotetext{
${ }^{2}$ The April 1986 issue of The Geneva Papers on Risk and Insurance was devoted to this issue.

${ }^{3}$ The material in this section is based on a comprehensive report on the current status of Environmental Liability Insurance undertaken by an Advisory Committee of the National Association of Insurance Commissioners published in September 1986. For more details see National Association of Insurance Commissioners (1986).
} 
Today there are practically no writers of gradual pollution coverage with the exception of the America Home Assurance Company and the Pollution Liability Insurance Association (PLIA). PLIA is a pool of over 40 companies that reinsures both sudden and gradual pollution coverage written by member companies using the ISO Pollution Liability Insurance policy. PLIA, however, does not insure chemical manufacturers, drug manufacturers or those who operate hazardous waste disposal sites.

Federal Environmental Legislation. Two recent pieces of Congressional legislation have had a significant impact on the insurability of damages from environmental pollution. These Acts were designed to protect public health and the environment through liability standards, regulations and enforcement procedures for owners and operators of hazardous waste facilities in the United States.

The Resource Conservation and Recovery Act of 1976 (RCRA). This is an extraordinarily complex federal environmental regulatory program which focuses on hazardous waste management. The principal purpose of the program is to consolidate federal statutes related to solid waste treatment and disposal so as to more effectively regulate existing and future waste disposal sites. For our purposes the most significant feature of RCRA is the requirement that all hazardous waste facilities have third party bodily injury and property damage against sudden and gradual pollution while the facility is operating.

After RCRA was enacted by Congress both domestic insurers and foreign reinsurers joined forces by offering environmental pollution coverage to satisfy the above financial responsibility requirement. By 1980 coverage in the $\$ 25-50$ million range was widely available. However, claims made against these policies grew rapidly between $1980-84$, leading to severe net losses in the industry. ${ }^{4}$ International reinsurers withdrew from the market and capacity for writing this type of coverage was reduced to practically zero (Kleindorfer 1986).

The Comprehensive Environmental Response, Compensation and Liability Act of 1980 (CERCLA). Better known as Superfund, this Act is designed to respond to releases of hazardous substances from currently inactive hazardous waste sites. It also provided $\$ 1.6$ billion for clean-up of these sites and long-term corrective action. The Environmental Protection Agency (EPA) has targeted 888 sites as urgently needing clean-up and has estimated that this number is likely to increase to between 1800 and 2000 in the next several years.

Two provisions in CERCLA have made it extraordinarily difficult for insurers to write coverage against pollution liability. For one thing the Act imposed strict liability on responsible parties for any damages or personal injury associated with cleaning up hazardous waste sites. This provision effectively makes parties retroactively liable for cleaning up hazardous waste sites even though they may have followed the best available technology or approved procedures at the time. In effect, the law requires that the insurer provide coverage against liabilities yet to be discovered.

When the source of a specific hazardous waste problem cannot reasonably be established, CERCLA imposed joint and several liability on generators, site owners, operators and transporters. Theoretically any party that handles or stores the waste is potentially

\footnotetext{
${ }^{4}$ The U.S. property and casualty insurers lost $\$ 21$ billion in 1984 and nearly $\$ 4$ billion in net losses. This was the first year since the 1906 earthquake that the insurance industry suffered net losses in this line of activity (Kleindorfer, 1986).
} 
liable for a substantial portion of the damage, no matter how careful the operation may be or how modern the equipment and methods. Insurers fear that liability for damages may be totally unrelated to the actions of the policyholder, especially when many of those who are potentially liable either cannot be identified or have become insolvent or bankrupt. Insurers see themselves as a "deep pocket" which will be viewed by the courts as a viable source for covering most of the damage should the insurers protect one of the responsible parties associated with hazardous waste management.

Congress reauthorized CERCLA through the Superfund Amendments and Reauthorization Act of 1986 (SARA). This legislation provides $\$ 9.2$ billion for cleaning up hazardous waste sites that are considered dangerous. In addition, the Act authorizes a study of insurability of hazardous substances to be undertaken by the Comptroller General of the United States and completed by October 1987. Unless contractors and waste management firms working on Superfund sites can obtain pollution liability insurance or are indemnified by the federal government from liability claims, they may be reluctant to engage in clean-up activities for fear of a large court case.

\section{Insurability Criteria for Environmental Pollution Liability}

Given the above institutional background the following hypothetical scenario will motivate the discussion of insurability issues:

Two industrial concerns (Alpha and Beta) dispose of their toxic wastes in a new state-of-the-art landfill which is lined with polyethylene and covered with a thin layer of clay and sited in a large trench. There is still a low probability of groundwater leachate which can contaminate the municipal water supply. Alpha would like to purchase environmental pollution liability coverage from the Cappa Insurance Company. Cappa knows that Beta is uninsured and has been studying whether it should provide coverage to Alpha. In fact, Cappa has been seriously investigating whether or not to provide this type of pollution coverage to many different industrial firms. What action should it take?

Berliner (1982) has specified a number of criteria for determining whether a risk such as environmental pollution liability is insurable. The relevant factors that need to be considered are :

* Probability of an Accident--How difficult is it to estimate the chances of groundwater pollution occurring leading to contamination of the municipal water supply? The more imprecise the estimate of the probability of such events, the harder it is to determine an insurance premium which accurately reflects the risk.

* Adverse Selection and Moral Hazard--Can Cappa detect a good risk from a poor one on the basis of a firm's behavior? To the extent that the insurer cannot differentiate between risks, it faces the possibility of adverse selection where only the poor risks will want to obtain coverage at a stated premium. Is there an incentive for Alpha to behave more carelsessly with respect to disposing of hazardous materials if it has purchased insurance? Is there any type of monitoring and control procedures that Cappa can institute to detect such behavior? 
* Probability of a Claim--If an accident occurs, what are the chances that a claim will be filed against the Alpha Company by users of the municipal water supply? The more difficult it is to determine the chances of such actions being taken, the more imprecise the insurance premium will be.

* Magnitude of the Loss--If a claim is filed what liability loss will Alpha be responsible for, what will the litigation costs be and what fraction of these costs will Cappa have to bear? What impact will the activities of Beta, who is uninsured, have on the losses attributed to Alpha (and hence Cappa)? To the extent that these losses are not well specified, then insurance becomes more difficult to write.

* Insurance Premium--What is the basis for determining an insurance premium to charge Cappa, given all the above factors? What data are available to underwriters on risk assessments of related events, the magnitude of related past claims, and the impact of liability rules imposed by the courts on future claims? If there is great uncertainty regarding the above factors then the insurance premium determined by underwriters would be so high that there would be no demand for coverage by Alpha or other industrial concerns.

The above criteria of insurability can be represented by a tree depicted in Figure 1 linking the probability of an accident and a claim to the magnitude of the loss due to Alpha (A) and Beta (B). More specifically, the probability of an accident $\left[p\left(D_{A}, D_{B}\right)\right]$ will be a function of the amount of waste disposed by Alpha $\left(D_{A}\right)$ as well as by Beta $\left(D_{B}\right)$. The probability Cappa will face a claim against $\mathrm{A}\left[q_{A}\left(D_{A}, D_{B}\right)\right]$ will be determined by amount of waste both the $A$ and $B$ forced deposit in the landfill, since there is no easy way to separate these two streams. Finally, if a claim is filed against $A$ there is a need to determine how much Cappa will be forced to cover, $\left(C_{A}\right)$. Each of these branches in Figure 1 will now be dissected more carefully.

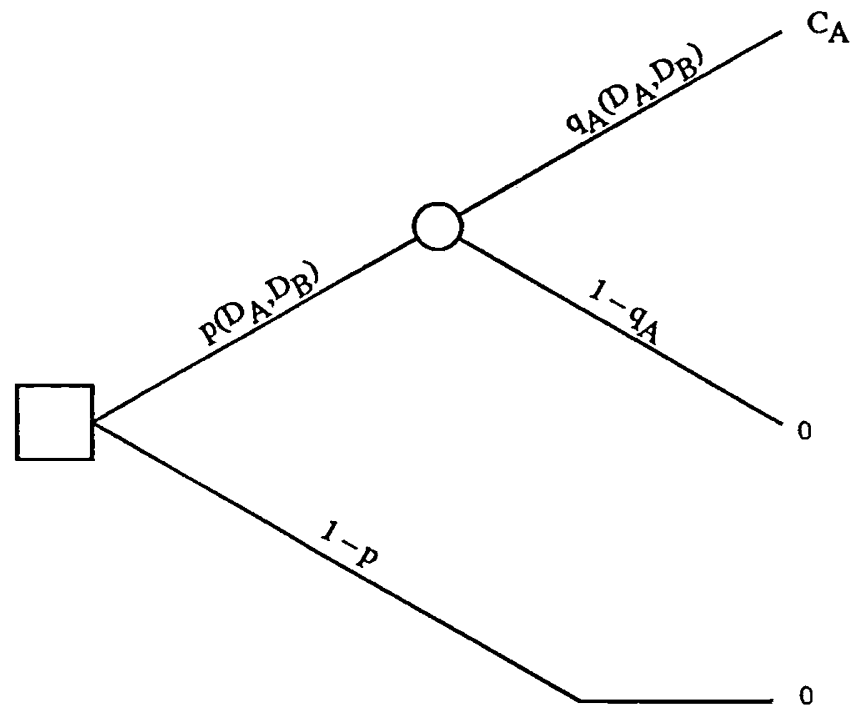

Figure 1. Branches of Decision Tree to Determine Insurance Premium 


\section{Probability of an Accident ( $p$ )}

Risk analysts have utilized fault trees and event trees to estimate the probabilities of an accident from a landfill. Both techniques rely on constructing a scenario associated with events that will lead to a particular failure and assigning probabilities to the various branches of the tree. The fault tree constructs a pathway leading to a specific event (e.g., sequence leading to core meltdown of nuclear power plant) while an event tree begins with a specific incident and follows its consequences to a logical conclusion. ${ }^{5}$ Figure 2 depicts an event tree for groundwater leaking from the Wellbent landfill. Specifically, a chemical disassociates itself from the solidifier. Leachate may or may not be contained by the plastic liner. If this spill is not contained then there is a question whether the monitoring system can detect contamination of the subsoil. The concentration is often detected by the municipal monitoring system which is mandated by the Safe Drinking Water Act. In this case Wellbent faces a fine. If the contaminant is undetected, residents may suffer diseases several decades later which will be attributed to the leachate. A jury may then find the company liable for the consequences.

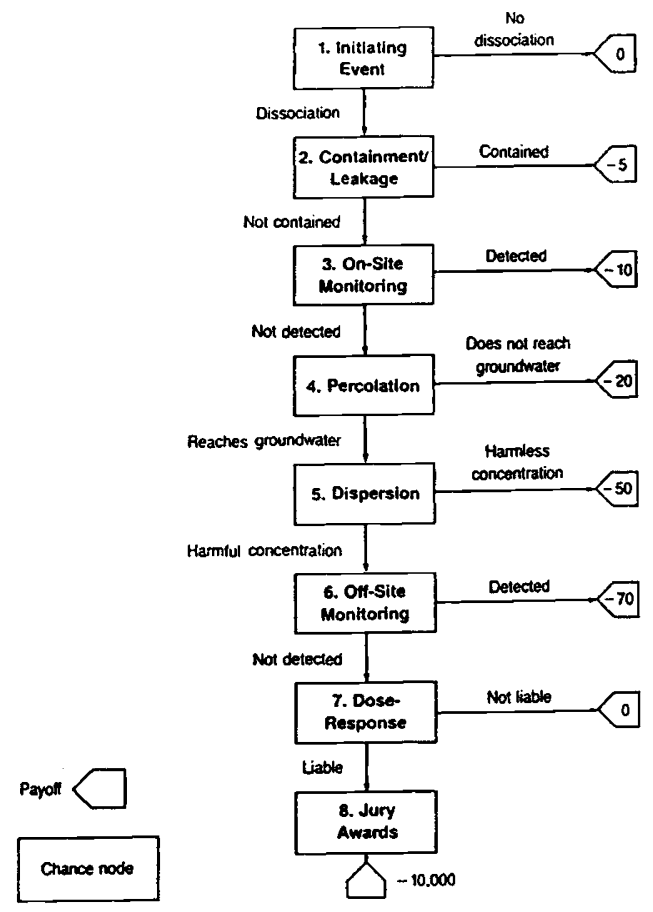

Figure 2. Event Tree that Traces the Potential for and Cost of Human Exposure to Ground Water Contamination. Adapted from Katzman (1985)

${ }^{5}$ A more detailed treatment of fault trees and event trees can be found in von Winterfeldt and Edwards (1986) pp. 52-55 
In order for such risks to be covered by insurance, probability estimates need to be made for each branch of the event tree. If the statistical data base on which to estimate this probability is sparse, it is hard to specify these figures with any degree of accuracy. Cappa needs to determine what type of confidence intervals must be placed on each of the probabilities associated with different losses as an input to their premium-setting process.

One of the principal difficulties in determining whether an accident has occurred (and its severity) is relating carcinogenicity to chemical exposure. There is a relationship between the dose of a chemical that a person has absorbed and the response to it. The risk assessment process normally consists of tests on animals which are then extrapolated to human beings. Few chemicals have actually been classified as toxic on the basis of these studies. Furthermore, the relationship between dose and response is highly ambiguous, particularly for low levels of exposure.

To illustrate why uncertainty about the dose-response relationship causes problems from an insurer's point of view, assume that an insurer is estimating the premium to charge to Wellbent against damage from its landfill. Suppose the chemical is known to have a probability of $p=.00001$ of reaching groundwater and contaminating an aquifier which serves 50,000 people. The estimated dose-response curve is utilized to determine the number who are likely to contract cancer should this event occur. Suppose a dose-response curve predicts ten persons per thousand and another dose-response curve predicts one person per thousand will suffer cancer for the $\mathrm{X}$ micrograms per liter of the chemical that will be presumed to leak from the landfill. Without knowing which type of curve -is appropriate, the insurer is uncertain as to what premium to charge. Even these calculations make a number of heroic assumptions regarding the amount of the chemical that leaks into the water supply. If there is also considerable uncertainty on the size of the leak then the problem of determining an appropriate premium is compounded further.

\section{Adverse Selection and Moral hazard}

There as been increased interest recently in the use of risk analysis and risk assessment by insurance companies for separating good from poor risks. (Baram, 1987). Due to the complexity of environmental risks there is a need for continuing surveillance over time. Insurers are now beginning to increase the size of their technical staff to undertake risk management activities. One company which has instituted such practices is American Home Assurance Co. which still issues environmental impairment insurance on a selective basis. As a condition for such insurance American Home experts undertake a complete risk analysis which is paid for by the prospective insured. (Kleindorfer 1986)

The difficulty in monitoring the landfill over time presents Cappa with a moral hazard problem once they issue insurance to $A$. If $A$ were utilizing the landfill alone then it would be possible to reduce such problems by instituting coinsurance and deductibles as part of the insurance policy (Arrow 1971). With Beta sharing the landfill, however, there is little that can be done to prevent this other firm from being careless in disposing of their waste.

\section{Probility of claim $\left(q_{A}\right)$}

There have been significant changes in the legal system in the United States which have greatly increased the chances that there will be a claim filed against Alpha should an accident occur. Some of these changes are due to recent environmental legislation, as indicated 
earlier, while others are due to the rapid changes in toxic tort laws which has significantly reduced barriers to recovery for personal injury and property damage. (Katzman 1985).

In traditional comon law Alpha would not be liable for damages if they had designed their landfill according to prescribed standards which represented the state-of-the-art (i.e., they would not be guilty of negligence). There would be a short statute of limitations with a time limit (normally 3 to 5 years) during which a person using water from the municipal aquifier could sue between exposure to a potentially hazardous chemical and the discovery of some injury (i.e., cancer). In addition, common law specifies individual liability so that the municipality must identify which of several sources have actually caused the harm. In the case of a landfill, more than one chemical company is likely to utilize the landfill. This would mean that municipality would have to show Alpha was at fault for polluting the aquifier.

The new toxic tort law has changed each of the above conditions. Strict liability now is sometimes invoked so that the court focuses on the risk itself rather than the behavior of the defendant such as Alpha. Several court cases have changed this burden of proof. For example, as early as 1868 , in Rylands versus Fletcher, Fletcher was found liable for escape of water from his land into a neighbor's mine shaft even through he was claimed to be nonnegligent. In the case U.S. versus Waste Industries, Inc., hazardous waste was considered to be an ultra-hazardous activity, so strict liability applies and the defendant is liable regardless of cause. As a result of this, the insurer is unsure whether strict liability, or some other (negligence) standard, will be applied. ${ }^{6}$

With respect to the time limit regarding court suits, the discovery rule has been invoked in 40 states. Under this principle, the statute of limitations applies to the discovery of an injury rather than exposure to the hazardous chemical.

Finally, the probability of a claim will be greatly affected by how the court interprets the wording of a contract. The most significant case in recent years relating to the definition of environmental pollution involved Jackson Township in New Jersey. In 1971 the township began to use a former mine, at which toxic chemicals had been illegally dumped, as its new landfill. Residents using shallow wells as sources of drinking water started to experience foul water and health problems. Since chemical contamination from the landfill was deemed to be the source of pollutants in the groundwater, they petitioned for the closure of the landfill. When the township passed a law requiring affected residents to hook up with the municipal water supply system, 97 of them responded with a lawsuit against the township. (Kunreuther 1987)

Jackson Township had purchased insurance against pollution that was caused by events that were "sudden and accidental". However, the court redefined this concept by interpreting it as "neither expected nor intended". Using this definition, any type of pollution, be it gradual or accidental, would be subject to claims in the future. For this reason, most insurers have excluded any type of pollution from their coverage today.

${ }^{6}$ For more details see Katzman 1985 and the issue of the Journal of Legal Studies, devoted to "Critical Issues in Tort law Reform: A Search for Principles", December, 1985. 
Magnitude of claim $\left(C_{A}\right)$

The above criteria are important factors in determining a meaningful insurance premium which reflects the risks. However, by themselves these factors do not preclude an insurer from offering coverage. The Cappa Company could always charge a rate based on either an extremely high probability of an accident and/or a claim. In other words, the above factors do not make environmental liability uninsurable.

In my opinion, it is the uncertainty of the magnitude of the claim settlement which is principally responsible for the failure of the environmental insurance market. The extent to which the law can go today can be illustrated with a simple example related to the scenario involving Alpha, Beta and Cappa.

Suppose that Alpha with net worth $\left(W_{A}=200\right)$ would like to purchase $I=50$ units of insurance coverage and Beta with net worth $\left(W_{B}=40\right)$ is uninsured against liability from leakage of the landfill. Cappa has been approached as a possible insurer for Alpha and is considering the potential size of the claim it would have to pay should there be an accident where the physical damage loss $(L)$ is estimated at 100 . Alpha is known to have deposited $20 \%$ of the waste in the landfill and Beta the remaining $80 \%$. Physical loss attributed to Alpha would be $L_{A}=20$ with the remaining 80 assigned to Beta. ${ }^{7}$ The following factors play a role in determining the magnitude of the claim:

* Joint and several liability. Under the concept of joint and liability Alpha would be responsible for whatever damage Beta could not pay even if A was only partially at fault. On the basis of this concept alone the magnitude of the loss to $A$ and the insurance claim would be :

$$
\begin{gathered}
L_{A}=\max \left[L-W_{B}, .2 L\right]=60 \\
C_{A}=\min \left[I, L_{A}\right]=50
\end{gathered}
$$

The concept of joint and several liability has been well established as a part of CERCLA and at the same time has been upheld in court cases. For example, the firm of $\mathrm{CH} 2 \mathrm{M}$ Hill, for a fee of $\$ 700$, took an air sample at a plywood plant in California and announced that the air was safe according to regulatory standards. In 1976, four years afterwards, an explosion at the plant left $\mathrm{CH} 2 \mathrm{M}$ Hill as the only non-bankrupt company involved and it had to pay the entire $\$ 1.6$ million settlement. (Main, 1986).

* Stacking of Coverage. Residents of the municipality where the accident occurred contend that the continuous damage process occurring with the gradual dispersion of a hazardous substance through the environment (e.g. water supply) triggers all insurance policies in effect during the period of dispersion. The courts have not firmly resolved this question. (National Association of Insurance Commissioners 1986).

In the above scenario should there be a stacking of policy limits and Alpha had purchased the same amount of insurance for two years the claim paid by Cappa would be:

$$
C_{A}=\min \left[L_{A}, 2 I\right]=60
$$

\footnotetext{
${ }^{7}$ The question of how one provides compensation if there is uncertainty regarding causality (e.g. cancer deaths) or more than one party is at fault has not been well handled under the current tort system. For an interesting approach to this problem see Lagakos and Mosteller (1986).
} 
* Defense Costs (D). Insurance policies in the past have not specified that the costs of defending the client is included as part of the policy limits. Courts have ruled that the costs of defending will be paid by insurers independent of any loss settlement. When insurers have been involved in court cases, litigation costs have comprised a large portion of the settlement.

For example, estimates of litigation costs for 1,800 cleanup sites on the Environmental Protection Agency's National Priority List range from $\$ 3.5$ billion to $\$ 6.4$ billion. These costs represent anywhere from 24 percent to 44 percent of the total settlement. Two examples illustrate the difficulties associated with determining the appropriate insurance companies responsible for the damage.

(1) Hooker Chemical, the only defendant at Love Canal, had insurance policies with 37 different insurance firms during the period in which the damage occurred. It was, therefore, difficult to decide which firm was liable and how to apportion costs.

(2) At the Rocky Moutain Arsenal, located northeast of Denver, Colorado, the U.S. Defense Department estimates it will spend $\$ 1$ billion dollars to clean up pesticides and nerve gas. Former Representastive Ken Kramer of Colorado has said that the arsenal has been called "the most contamined piece of ground in the free world". Shell Oil, one of the two defendants (the other is the U.S. Army), indicated it has insurance with 245 firms during the period in which the damages allegedly occurred. (Rich 1985).

For this example assume that $D=30$ and that Cappa will have to pay this amount if there were a court case. Then the revised estimate of claims costs are :

$$
C_{A}=D+60=90
$$

* Stress and Mental Anguish (S). Tort law permits recovery for mental anguish or worry by plaintiffs who can demonstrate actual damage. In the Jackson Township case the jury broke precedent by granting financial recovery to residents of the municipality based solely on worry. There was not sufficient evidence in the case linking chemicals to any physical injury. The initial ruling of the jury provided $\$ 8.2$ million dollars for lifetime medical surveillance, $\$ 5.4$ million for "impairment of quality of life" and $\$ 2$ million for emotional stress. (Katzman 1985). One appeals court has reduced the settlement to $\$ 5.4$ million but the general principle associated with psychological factors is still intact.

Suppose that for the above scenario $\mathrm{S}$ is estimated to be 50 so that $L_{A}=110$. Cappa now estimates that claims costs will be:

$$
C_{A}=D+\min \left[L_{A}+S, 2 I\right]=130
$$

Definition of Occurrence. Courts have also debated whether a continuous release of a hazardous substance constitutes a single occurrence or whether a release may be divided into discrete sections of either separate drops, leaks, days or damage events. In the latter case there are legitimate disputes as to the applicable limits of liability under the insurance policy. (National Association of Insurance Commissioners 1986)

In the Jackson Township case the court decided that each of the individuals in the 97 families (i.e. over 300 persons) who filed claims for damage were treated as separate policies. In other words, if an insurance company had a policy limit of $\$ 1$ million against drinking water damage, this would have been applied to each individual. Theoretically, the insurance company would be liable up to a maximum of $\$ 300$ million. 
Under such a ruling Cappa would have to guess how many people $(\mathrm{N})$ might be affected before it could estimate its potential claim settlement. Continuing with the above example, suppose that Cappa projects from the Jackson Township case so that it estimates $N=300$. In this case if we assume that the losses are the same for each individual and the aggregate defense costs are $\mathrm{D}=200$, then

$$
C_{A}=D+N \min \left[2 I, L_{A}\right]=30,200
$$

It should be clear from this extended scenario that what appeared to be a straightforward claims calculation has ballooned into a figure which has no relationship to the original policy limits.

\section{Insurance premiums}

When each of the three critical elements which determine an insurance premium ( $p$, $q_{A}, C_{A}$ ) are fraught with uncertainty, it is difficult for an insurer to determine a premium that customers are willing to pay. Studies of the response of actuaries to ambiguity regarding probabilities of losses reinforces the conclusion that they will significantly raise the premium even if the loss is well known. (Hogarth and Kunreuther 1987). ${ }^{8}$

The Premium/surplus ratio, a standard measure for judging the solvency of companies, has reduced capacity even further due to large losses. This ratio is considered an important financial indicator by the National Association of Insurance Commissioners, as part of an early warning system of potential insolvencies. Regulators use this ratio to determine whether a firm has overcommitted itself by writing too many policies in relation to its assets. Premiums are thus used as a surrogate for potential liability. When this ratio exceeds 3 regulators are concerned and may examine the financial status of the firm in more detail.

The use of this ratio is largely responsible for what is termed the "underwriting cycle" and has had an adverse effect on capacity. When large losses occur this naturally reduces surplus and raises the $\mathrm{P} / \mathrm{S}$ ratio. Insurers are then interested in raising premiums to avoid future losses but, of course, this action would only raise the $\mathrm{P} / \mathrm{S}$ ratio even further. The only recourse open to insurers to keep the ratio below three is to reduce their capacity.

$\begin{array}{ll}\text { Example } & \text { Surplus }=\$ 30 \text { million } \\ & \text { Premiums }=\$ 90 \text { million } \\ & \text { Premium } / \text { Surplus Ratio }=3 \\ & \text { Losses for } 1985=\$ 100 \text { million } \\ & \text { Surplus }=\$ 20 \text { million } \\ & \text { Premium / Surplus }=4.5\end{array}$

Table 1 : Impact of Large loss on Premium/Surplus (P/S) Ratio

\footnotetext{
${ }^{8}$ It should be pointed out that Henri Smets concludes from OECD countries that frequency and severity of losses to date from air, noise, oil, transport and hazardous waste are well within range of insurability in that these loss distributions are similar to those encountered in areas like airline accidents where insurability has not been a problem. (Smets 1987). A principal difference between environmental liability and airline accidents, as indicated above, is how the tort law treats accidents. Airline settlements are much more predictable than environmental pollution cases.
} 
An illustrative example of this point is presented in Table 1. Suppose losses for Cappa in 1985 exceeded earned income (i.e., premiums plus interest) by $\$ 10$ million dollars, thus reducing its surplus from $\$ 30$ to $\$ 20$ million dollars. A reduction in surplus immediately raises the $\mathrm{P} / \mathrm{S}$ ratio to a higher level (e.g., from 3 to 4.5 ). If Cappa faced this situation they would want to raise their premiums to deal with the large loss, but this action would raise the $\mathrm{P} / \mathrm{S}$ ratio even higher. If new capital were not available from the money markets then there would be a shortage of capacity so that Cappa would not offer or renew certain types of policies in order to cut premiums from $\$ 90$ to $\$ 60$ million dollars so the P/S ratio would again be about 3 . Coverage for highly uncertain risks, such as EIL, would be the first type of policy to be cancelled under this type of financial crisis.

\section{Comparison with Automobile Coverage}

A comparison of EIL insurance and liability coverage against an automobile accident highlights the difficulty in setting premiums by underwriters and actuaries.

Estimates of the probability for EIL are highly ambiguous because of its limited statistical history. The probability of a claim and the magnitude of loss are poorly defined because causality is not clearly understood. Cancer, for example, is a product of many different factors, not just of groundwater pollution, and diseases of this kind have a latency period of many years after individuals have been exposed to chemicals. Finally, the catastrophic potential associated with damage caused by pollution exposes the insurer or reinsurer to the possibility of extraordinary large claims.

In the case of automobile coverage, there is a well-defined probability, based on a long history, for any accident. The losses are well-defined, either in terms of property damage or liability coverage for injuries or fatalities, and there is a well-defined legal definition as to who is at fault in an accident. Furthermore, the events are sudden and normally involve few parties (usually one or two cars). All these factors make the risks of automobile accidents much easier to insure at reasonable premiums than those of environmental pollution.

\section{Proposed Solutions ${ }^{9}$}

The principal benefit of industry's failure to obtain pollution insurance is that firms are now cleaning up their act. Chemical companies have been modifying their production processes so as to reduce the amount of toxic wastes to be disposed. In addition, they are relying on cleaner means of dealing with their wastes through incineration rather than landfills. Due to problems of joint and several liability large firms are disposing of their own waste and not letting anyone use their on-site incinerator. Yet with the exception of the very largest industrial concerns, most firms have a need for pollution insurance. Not all the proposed solutions to the insurability problem address efficiency issues. Rather they are presented here as a set of alternatives which may help restore the EIL market.

\footnotetext{
9 This section is based on the conclusions of the small group discussion at the Wharton School Workshop on "The Role of Insurance and Compensation in Environmental Pollution Problems". A summary of these findings also appears in Kunreuther (1987).
} 


\section{Revision of Liability Rules}

One of the most obvious solutions for breaking the current gridlock in EIL insurance is a revision of the CERCLA joint and several liability provision. The principal problem with joint and several liability as it is now structured is that it is difficult for an insurer to know how much loss to expect. For example, if a number of firms are disposing of waste in a landfill, it is difficult for Alpha's insurer to know either what Beta and other disposers of waste in the landfill are doing or what its client's share of damages would be in the case of a claim.

Participants in the Wharton School workshop called for a compromise between joint and several liability and individual responsibility. They suggested that the parties with the "deepest pockets" should not be the only ones held liable in case of an accident. For example, parties responsible for a large portion of the waste in a landfill should be forced into a measure of responsibility.

A similar redefinition might be needed to protect insurers from retroactive liability by setting the standard of "best engineering judgement". A firm would then not be found negligent for using the best technology available at the time if, in the future, new developments make these earlier methods of operation inappropriate.

A more sweeping reform that might lure insurers back into the fold would be the separation of cleanup costs from those for insurance of victims' compensation. The costs of personal damage might be administered through a national compensation fund or a national health insurance for victims' compensation. Insurers would then be directly liable only for economic loss rather than for pain and suffering as well.

\section{Better Definition of Contract Terms}

The Jackson Township case illustrates the extent to which the court can interpret phrases like "sudden and accidental" to include gradual pollution and latent diseases. The judiciary should make some explicit statements on what is included and excluded from a particular insurance contract. The insurance industry and state legislatures are taking several steps to deal with this problem.

${ }^{*}$ Insurance contracts are being written so that the costs of defending the case are included in upper limits of coverage and insurers' total expenses are limited to this amount. Previously, if an insurer that provided a company with $\$ 1$ million of coverage was forced to defend a suit that cost it $\$ 3$ million for litigation expenses, the insurer would be forced to pay not only defense costs, but claims costs as well.

* Several state legislatures have placed a cap on the enforceable upper limits of loss. For example, Maryland has placed a $\$ 350,000$ limit on awards for pain and suffering and personal injury, and a special commission in New York has recommended a $\$ 250,000$ cap for awards against municipalities for pain and suffering. The kinds of actions may enable insurers to have a better handle on what their contracts will and will not cover.

Stopgap insurance options are few and far between today, but at least 37 states have legalized "claims-made" policies. Under such policies the insurer protects a company against claims filed during the policy year for accidents that occurred during an earlier time period. The insurer, however, is protected from future claims made after the expiration of the policy. 


\section{Joint Private-Government Programs}

Several alternatives present themselves for the government to be involved in providing coverage for catastrophic losses which cannot be covered by normal insurance or reinsurance mechanisms. It is particulary true for environmental pollution damages where the upper limits can be extraordinarily high, given recent toxic tort interpretations.

One alternative that may be worth investigating is to have insurers/reinsurers pay a premium to the government for protection against unusually large losses. This type of program resembles the National Flood Insurance Act whereby private companies market coverage to individuals and businesses but are protected against large losses through such a government reinsurance program. However, it is not apparent that government reinsurance is superior to private reinsurance, assuming the latter is available.

A second and more reasonable alternative is to have private insurers responsible for paying a prespecified amount of claims. This type of program would be modeled after the Price-Anderson Act for nuclear power, whereby private insurers pay $\$ 160$ million dollars for damages and the government covers additional $\$ 400$ million if necessary. If damages exceed $\$ 560$ million dollars, specific congressional legislation would be needed to pay victims for this additional loss.

A third alternative is for some type of government indemnification program whereby provide it compensation to victims. A key issue in the administration of this program is separating out genuine claims from bogus ones. In other words, there are potential moral hazard problems, particularly since causality is difficult to establish and specious reasons may emerge.

\section{Possessory Liability and Channeled Cleanup Liability}

Leslie Cheek (1986) has proposed these two alternatives as ways of dealing with CERCLA regulations regarding hazardous waste disposal. Under a system of possessory bodily injury and property damage liability insurance, coverage would be provided against well defined sudden accidents while potentially hazardous substances are in the possession of an insured business. Thus, if a generator's on-site holding tank ruptures, the firm and its insurer would be liable for any bodily injury or property damage caused by the release. Similarly, if a transporter's truck overturned en route from a generator's premises to a disposal facility, the transporter and its insurer would be liable for any bodily injury or property damage caused by the spill. The policy would have to exclude damages for mental or emotional distress in the absence of clinically diagnosable injury. Costs such as medical surveillance should be explicitly excluded from coverage.

Under channel cleanup liability the facility owners would be required to accumulate reserves for onsite cleanup to cover the costs associated with accidents such as leakage of toxic substances. By instituting such a system insurers would only be liable for bodily injury and property damage from a facility rather than for cleanup costs. Funds for these reserves could be raised through additional assessments to facility owners and to those making use of the disposal facilities. 


\section{Risk Retention Groups}

Another solution proposed to make EIL insurance available is the establishment of Risk Retention Groups. These are basically Group Insurance companies that are mandated by special legislation, and which are exempt from certain state regulations normally required of insurance firms.

Originally introduced in the product liability area by Federal statute, they have recently been extended to pollution liability. Risk Retention Groups are expected to reduce insurance costs for some businesses. For example small firms, which have had good claims experience, but have not benefitted from that experience under prevailing insurance ratemaking systems, would now have to pay lower premiums. Risk Retention Groups are also expected to provide greater competition and encourage private insurers to set rates that reflect the cost of coverage as accurately as possible. Such companies are also expected to ensure prompt payment of legally valid claims.

\section{Subrogation}

Kenneth Abraham (1986) suggests that one way for insurance to serve both as an efficient and timely compensatory mechanism and as a deterrent against pollution is to institute a subrogation mechanism. The companies involved in hazardous waste disposal would contribute to a compensatory damage fund through which victims would receive rapid compensation. The fund would then file suit against the allegedly responsible companies to recover the damages from them. This process would not be subject to the pressures for quick settlement as are the processes currently in effect. Because firms know that they will probably be held accountable for the damages if they are at fault, they would practice better risk management in order to prevent loss. Insurance would cover the damages in question, but better practices would be encouraged because future premiums would be set on the basis of the nature of the firm's operations.

The crucial problems associated with environmental impairment liability, such as the identification of the probability of an accident and the magnitude of loss, do not, however, disappear under subrogation. The only way to deal with these issues seems to be to obtain better statistical data on past loss experience, improved models on the causes and effects of illnesses and damages related to toxics, and a clearer idea as to the nature and range of future losses from court settlements.

\section{Research Needs}

Long-term solutions to the problems of environmental liability must be preceded by better knowledge, both qualitative and quantitative. Participants at the Wharton School workshop suggested a set of research goals that would be useful in developping measures for coping with the problem.

* What kind of boundaries can be established for the relevant data ? For example, estimates of the costs of cleaning sites range from $\$ 16$ billion (EPA) to more than $\$ 100$ billion (Office of Technology Assessment). There are also widely ranging estimates of the percentages of the population who are victims of environmentally caused cancer. What are the reasons for these differences? 
* What is the appropriate role of risk assessment ? What must be known even to deal with the question? Can we define risk? If we do not like the rules of the game, what institutional changes can be made? Is change going to help if there is a continuous spate of new legislation?

* What is known about the frequency and severity of past claims from environmental pollution policies ? Can the nature of an occurrence be defined explicitly (for example, when a leak starts, when someone drinks the contaminated water, or when the person falls ill)?

* The standard contract clauses are in disarray. Is it possible to develop terms other than sudden and accidental that will hold up in courts more successfully? What is the definition of a "clean" site? How clean is "clean" ? How safe is "safe" ?

* Some people who are concerned about high awards to victims suggest that the terms of an insurance policy are controlled by a tort system designed to impose individual responsibility but using the rules of collective responsibility for enforcement. The combination is seen as the worst of both worlds. What are the pros and cons of each system as a first step towards establishing a coherent, unified insurance process ? Should the oil and chemical industries fund the compensation programs? If they did, they would, in effect, be insurance companies, passing the cost of compensation on to society through the sale of their products. What is the proper mechanism for spreading the cost--the companies, the government, or the insurance industry?

* What are the patterns of recent court decisions at both the federal and state levels? What can be said about the costs of settling a case, the time of litigation, and the rationale of judges in instructing juries? Since arbitration is an alternative to court cases, how do the costs of each kind of procedure compare? How often do court decisions really surprise the insurance industry by changing the intention of a clause in a policy?

* What is the experience of government involvement with other types of related insurance--black-lung disease insurance, flood insurance, nuclear power coverage, and workmen's compensation? Are there lessons from these types of coverage that are relevant to environmental impairment liability coverage?

* What can be learned about EIL insurance in other countries ? Can the American system of contingency fees, for instance, be usefully quantified and matched against the Britsh system ? What are the aggregate settlements in each country ? People who live within a certain radius of a plant in Japan and come down with a disease associated with a product or raw materials from the plant receive compensation. Yet what cultural differences--for instance, the American adversarial system--make potential adoption of this kind of compensation difficult if not impossible in today's environment?

* There is a general perception that insurance premiums are high and the supply of insurance is lacking--yet insurance needs are great. Why, in the tradition of the free-enterprise system, have so few new insurers entered the market, tried to understand the risks, and issued insurance policies against them? 


\section{What Can be Done Now}

It appears that there is sufficient concern from interested parties--insurance companies, hazardous waste cleaning firms, Congress, and environmental groups, for example-for solutions to the problem of EIL insurance to emerge in the near future. One way to approach the problem of EIL insurance is to systematically investigate the impact of different legislative provisions and legal rulings on the ability of insurers to provide protection under standard policies (when a premium is paid by a client for a stated amount of coverage). What impact have joint and several liability, retroactive liability, and the discovery rule had on the viability of insurance ? This approach will provide a baseline from which to investigate alternatives for dealing with the situation.

A more positive course of action would be to analyze the role that ambiguity and uncertainty play in the environmental liability area, the role risk assessment can play in the process, and how alternative forms of insurance involving consortiums of firms or more active government involvement might emerge to fill the current void. All these programs, however, depend on some predictability about the determinants of liability and about future court rulings regarding claims settlements.

There is also a need for an analysis of the role played by regulations and standards in encouraging industries to improve storage and disposal of hazardous materials. There is considerable evidence that the insurance crisis, coupled with current regulations, has directed most large chemical and manufacturing companies away from landfills to safer disposal methods such as incineration. Furthermore, these firms have modified their production processes so that there are less hazardous materials for disposal. Linking better practices to lower insurance premiums through risk assessment methods should capitalize on one of the most important functions of insurance: prevention of accidents.

Finally, there is a need for a continued dialogue between all of the interested parties in this debate. Only in this way can we explore together the relative costs and benefits of different programs in a constructive manner.

\section{BIBLIOGRAPHY}

ABRAHAM, K., Distributing Risk, New Haven, Yale University Press, 1986.

ARROW, K.J., Essays in the Theory of Risk Bearing, Chicago, Markham, 1971.

BARAM, M., "Chemical Industry Hazards: Liability, Insurance and the Role of Risk Analysis", in Kleindorfer and Kunreuther, Insuring and Managing Hazardous Risks, Heidelberg, Springer Verlag, 1987.

BERLINER, B., Limits of Insurability of Risks, Prentice-Hall, Englewood Cliffs, NJ, 1982.

CHEEK, L., "A Concept Paper: Possessory BI/PD Liability and Channeled Cleanup Liability for Hazardous Waste Disposal" (mimeo) 1986.

HOGARTH, R. and KUNREUTHER, H., "Risk, Ambiguity and Insurance", Working paper, Risk and Decision Processes Center, The Wharton School, University of Pennsylvania, 1987.

KATZMAN, M., Chemical Catastrophes, Homewood, I11., Richard D. Irwin, 1985. 
KLEINDORFER, P., "Environmental Liability Insurance: Perspectives on the U.S. Insurance Crisis,"Working paper, Risk and Decision Processes Center, The Wharton School, University of Pennsylvania, 1986.

KLEINDORFER, P. and KUNREUTHER, H., (eds) Insuring and Managing Hazardous Risks: From Seveso to Bhopal and Beyond, Heidelberg, Springer-Verlag, 1987.

KUNREUTHER, H., "Gridlock in Environmental Insurance: The Failure of EIL Coverage" Environment, January/February 1987.

LAGAKOS, S. and MOSTELLER, F., "Assigned Shares in Compensation for Radiation Related Cancers," Risk Analysis 6: 345-357, 1986.

MAIN, J., "Who Will Clean Up ?" Fortune 17: 96-102, March 1986.

National Association of Insurance Commissioners, (NAIC) "Report of the NAIC Advisory Committee on Environmental Liability Insurance", September 1986.

RICH, B., "Environmental Litigation and the Insurance Dilemma", Risk Management, Dec. 1985 , pp. 35-41.

SMETS, H., "Compensation for Exceptional Environmental Damage Caused by Industrial Activities", in Kleindorfer and Kunreuther, Insuring and Managing Hazardous Risks, op. cit.

VON WINTERFELDT, D. and EDWARDS, W., Decision Analysis and Behavioral Research, Cambridge, Cambridge University Press, 1986. 